\title{
A ROLE FOR LICHENS IN BOTANIC GARDENS?
}

\author{
Christopher J. Ellis ${ }^{l}$
}

\begin{abstract}
Lichens are biologically diverse and ecologically important. They infuse a botanic garden with character, and are sensitive indicators for the health of our environment. Their continued recolonization of botanic gardens should be celebrated, yet is frequently greeted with trepidation. Acknowledging the under-played significance of lichens and other cryptogams, PlantNetwork organized a conference on Mosses, Ferns and Lichens in Gardens (September 2007). This article summarizes a talk presented at the PlantNetwork conference. It discusses the role of lichens in botanic gardens, and also includes general themes (aesthetics, monitoring and education) which may be applied across other cryptogam groups, for example mosses, liverworts, ferns and non-lichenized fungi.
\end{abstract}

\section{INTRODUCTION}

Lichens are one of biology's most famous symbioses. A fungus builds the lichen structure, in which it 'farms' a population of algae or cyanobacteria, harvesting photosynthetic products, and protecting its 'photobiont' from environmental stress. This symbiosis evolved at least 450 million years ago, and is now important in terms of both biodiversity and ecology. There are an estimated 35,000 lichen species globally, they are almost ubiquitous in terrestrial habitats, and they are ecologically important in terms of productivity, nutrient cycling and soil stabilization across vast ecosystems. Despite their strong appeal to the naturalist with a weakness for unsung heroes, there can't be many people that have visited a botanic garden specifically to admire lichens. Nevertheless, an increased richness of species and wider range of lichen growth-forms is quite evident in many city botanic gardens, compared to the urban sprawl outside the gates. For those happy few, lichens will add an extra dimension to a botanic garden visit. Other people perhaps less familiar with the natural world frequently and needlessly worry that newly observed lichens are an odd and sinister presence, invading the garden and severely damaging otherwise healthy trees. Perhaps most frequently, lichens add to the essence of a garden, without being specifically credited. In this paper I summarize a talk given to PlantNetwork in September 2007, concerning the role of lichens in botanic gardens. I presented three main themes characterizing the relationship between lichens and botanic gardens, dealing with aesthetics, environmental monitoring, and education.

${ }^{1}$ Christopher Ellis is a Conservation Officer at the Royal Botanic Garden Edinburgh. Address: Royal Botanic Garden Edinburgh, 20A Inverleith Row, Edinburgh EH3 5LR. Email: c.ellis@rbge.org.uk 


\section{AESTHETICS}

As far as lichens are concerned, botanic gardens comprise a wide spectrum of landscapes. At one extreme is the highly formal garden, that is the sort of place with raked gravel pathways, polished stone statuettes, and topiary. If the horticulturists are diligent, and aim to remove all aspects of contingent biodiversity, leaving only what is planted and pruned, then I expect the lichens generally feel unwelcome in this extreme gardenscape. Lichens can, apparently, make a place look scruffy. At the other extreme is the natural world, glorious in its rampant scruffiness. Our native woodlands, rockfaces and bouldery soils are the original home in which patterns of lichen biodiversity

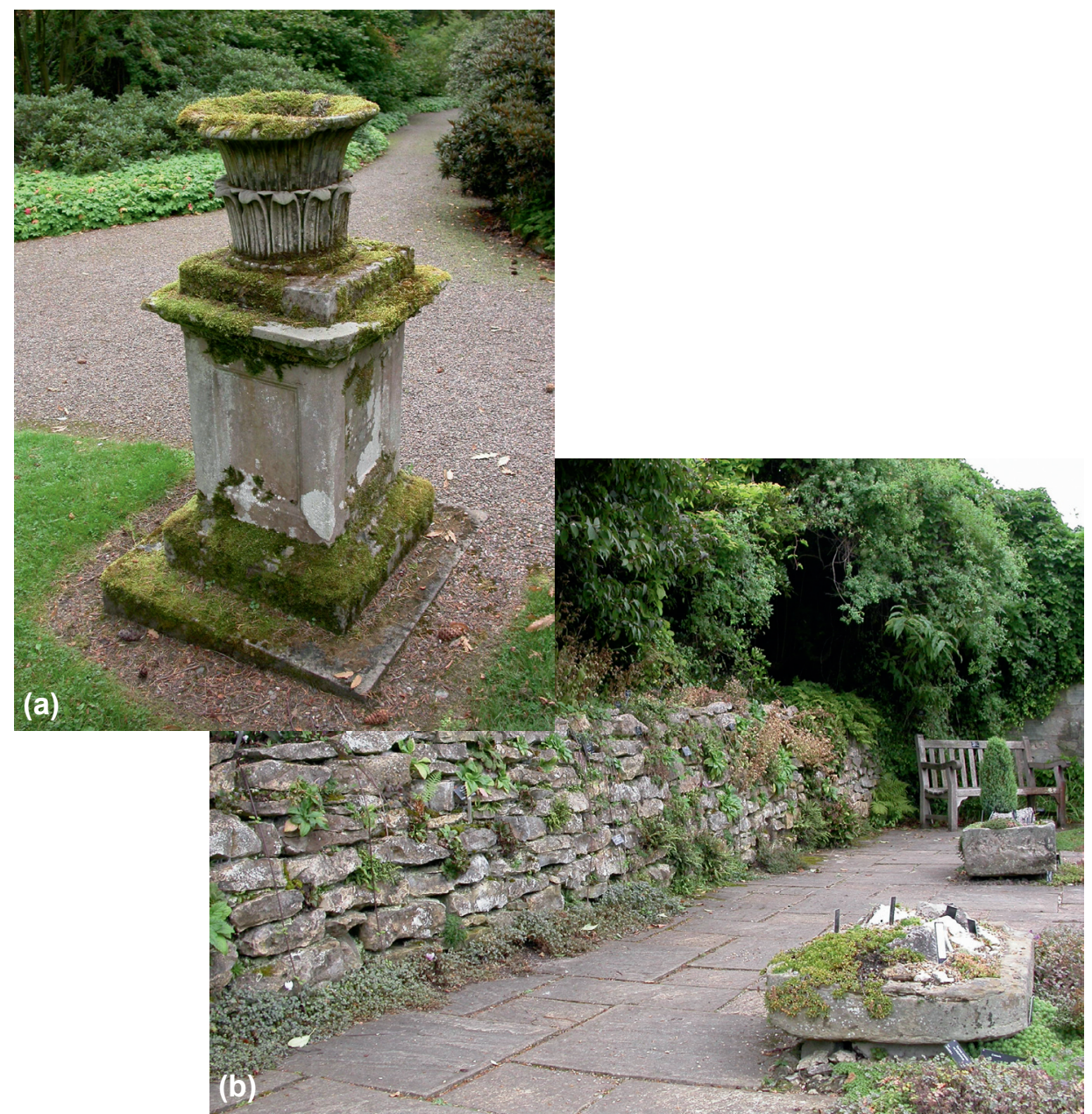

Fig. 1 Examples of cryptogams in botanic gardens: (a) A stone plinth and urn at Dawyck Botanic Garden festooned in lichens and mosses; (b) cryptogams on the stone troughs and wall in the Alpine section (RBGE). In both cases cryptogams enhance the visitor experience. Photos: C. Ellis. 
ideally respond unfettered to the wider environment. The botanic gardens most loved by lichenologists are probably those which exist between these extremes, and which cleverly work with nature, rather than exerting a total control. These gardens are undoubtedly managed (of course!), but in a sympathetic way creating a sensation which emphasizes admiration for the natural world, and provides a deep sense of harmony. Lichens have a strong aesthetic role in these gardens. It is a paradoxical role in which the individual lichens mostly go unnoticed, while the 'feel' they lend to a place is at the heart of its character. A prime example is Dawyck Botanic Garden, near Peebles. Dawyck is a relatively small garden which feels vast, and the visitor can wander for hours along a maze of pathways. It is possible at Dawyck to feel the excitement of discovering parts of the garden which seem lost in time. This timeless feel is in no small part owing to the richness of lichens and mosses which festoon the trees and coat the stone work (Fig. 1a). Together, the wealth of lichens and their inter-play with the gardened landscape lend a justified and ancient air, contributing to a deeper experience and one which would be devalued if this contingent biodiversity were purposefully removed. A smaller-scale example at the Royal Botanic Garden Edinburgh (RBGE) is provided by the wonderful stone troughs which form a feature of the Alpine section (Fig. 1b). These old and weathered troughs are the perfect frame for the hardy alpines, and are greatly admired. Yet how many admirers question more deeply their liking for the troughs? To be crass, to what extent would the Alpine section be devalued if the horticulturists had instead chosen the cheap and easy option and bought a dozen new concrete troughs from B\&Q? It is of course the lichens and mosses which lend each trough its unique craggy and weathered aspect, thereby stamping the planted features with genuine authenticity.

It is notoriously difficult to purposefully manage lichens within the garden landscape. They cannot usefully be grown under glass, and if one moves them from one place to another they have a strong tendency to wilt and die. As a consequence, the vast majority of lichen conservation is in situ, dependent on ecologically-informed habitat management. We don't have the expertise to reliably archive lichens in a living collection, and if their wild habitats are lost, so too are the lichen species which occupied them. It is however possible to encourage lichens within the garden, particularly by building structural complexity, and following simple rules. A general misconception is that lichens grow best in damp and shady places. This is true of some lichen species, though the rule is perhaps far more suited to mosses. A greater diversity and richness of lichen species will be found in open aspects, which experience periods of wetting and drying. Fewer lichens will be found where trees are closely grown, or where species cast a deep shade, such as our native beech (Fagus sylvatica). In contrast, lichen epiphytes prefer an open and gladed parkland-type structure which is probably typical of many botanic gardens (Fig. 2). Structural complexity comes easy to a botanic garden, and lichens will respond to a range of micro-habitat factors, including the roughness of tree bark, its chemistry and hardness, and the different geologies in a rock garden. With this inherent structural complexity, the occurrence of lichens is only limited by time for 


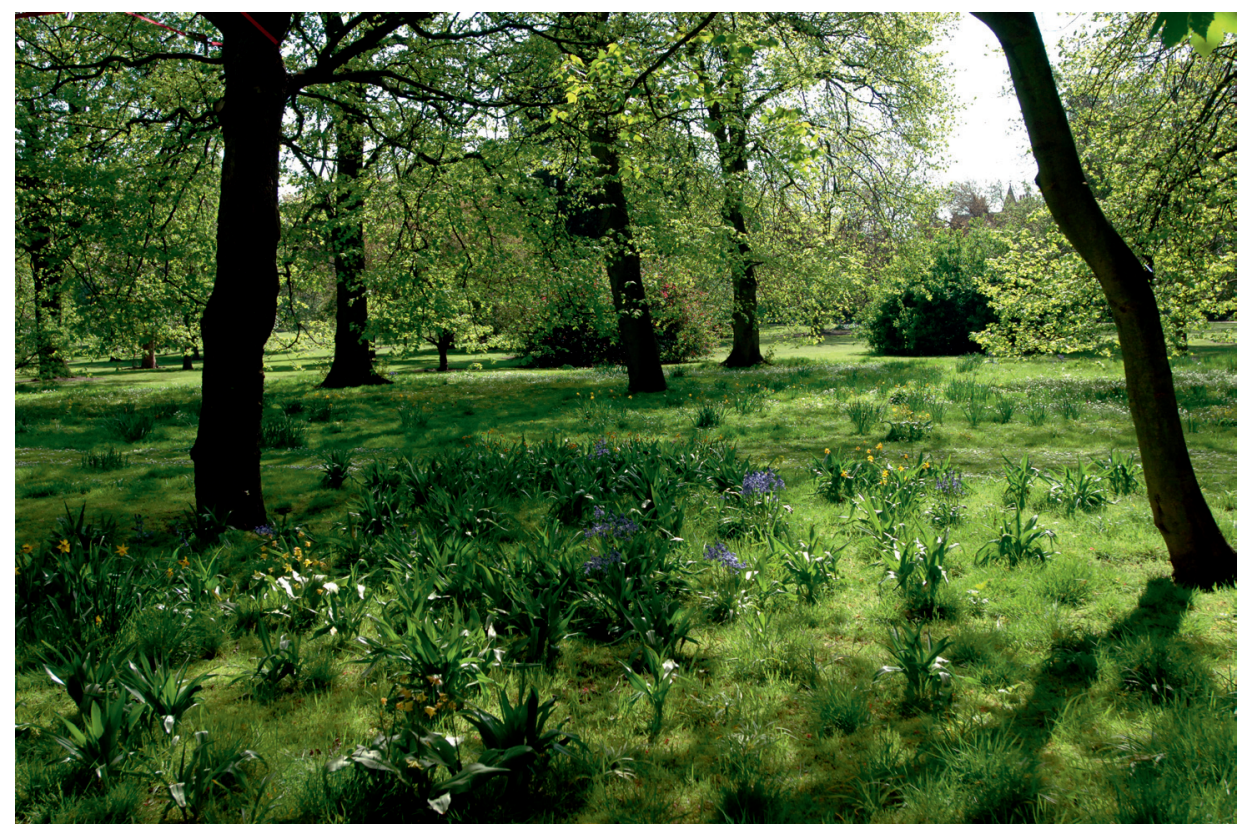

Fig. 2 A parkland-type structure in the Royal Botanic Garden Edinburgh. These well-lit and gladed settings are suitable to the growth of lichen epiphytes. Photo: Lynsey Wilson.

colonization and growth (which can be more rapid than is generally appreciated), and human degradation of the wider environment (for example the widespread effects of air pollution).

\section{ENVIRONMENTAL MONITORING}

Lichens occur in the coldest places on Earth, on the summits of the world's highest mountains, and in the coastal inter-tidal zone. They occur in streams, rivers and lakes, and in the world's driest deserts. In a rather strange experiment they were even sent into space, and survived weeks of exposure to the rigours beyond Earth's atmosphere. Perhaps even more surprisingly, the first attempt to launch the experiment failed when the rocket exploded. When the crash site was visited (several months later) the lichens had survived the explosion, and were happily growing! Oddly, despite this natural toughness, lichens are extremely sensitive to human degradation of the environment, especially in the form of air pollution. Additionally, different species have contrasting tolerances to environmental limits (for example climatic factors), so that lichen communities have a 'signature', which can be applied as an environmental bioindicator. 


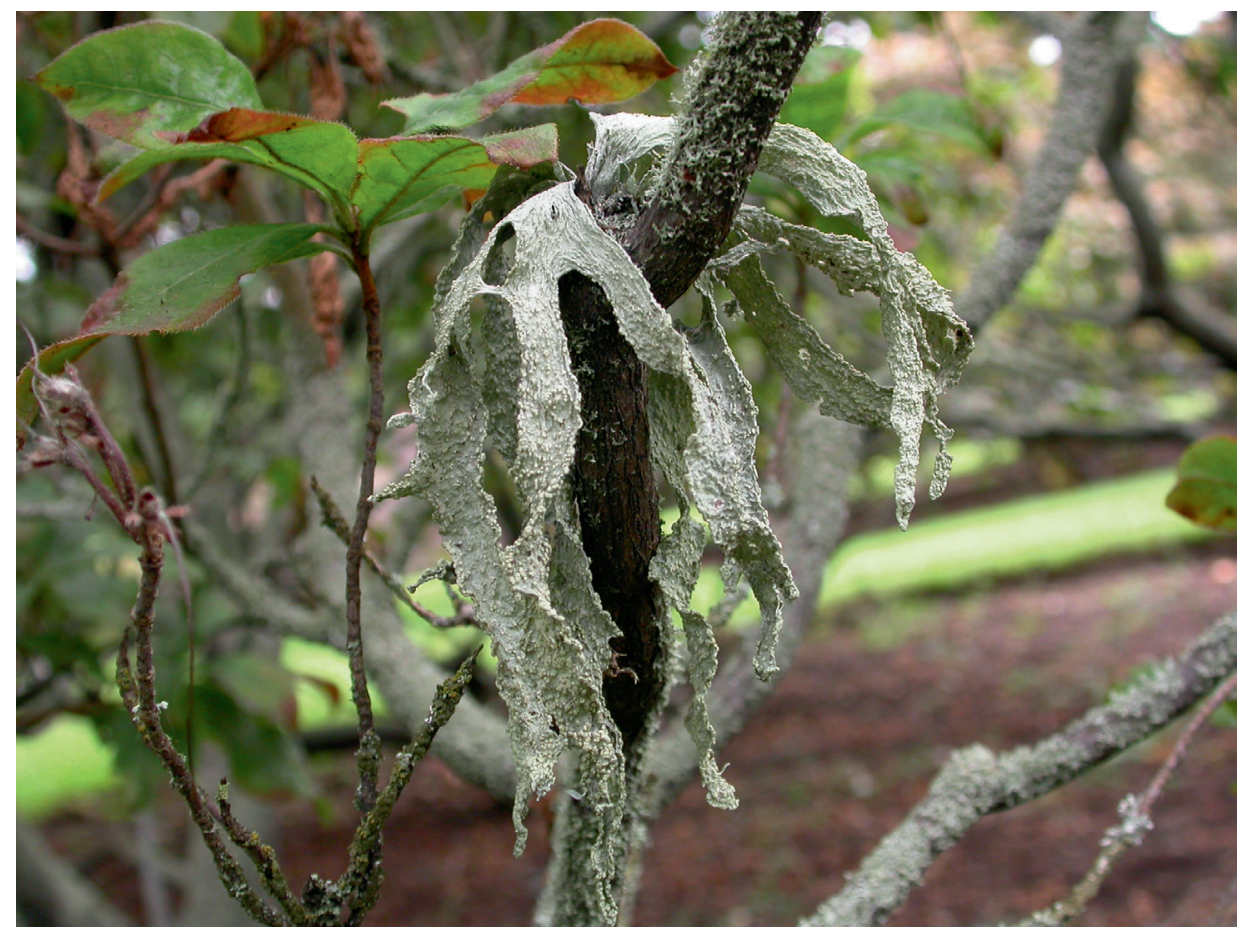

Fig. 3 Hanging pendulously from the branches of an azalea, Ramalina fraxinea is a pollution-sensitive lichen. It has recently made a return to Edinburgh following more than 200 years of absence. Photo: C. Ellis.

A network of botanic gardens provides an ideal large-scale study system, in which a secure programme of co-ordinated monitoring could (and should) be carried out. Climatic effects on communities can be observed between gardens. For example, the presence of Sticta fuliginosa and S. sylvatica, and Peltigera horizontalis and P. praetextata, at Benmore Botanic Garden (near Dunoon) testify to its strongly oceanic character. This contrasts with the presence of 'southern' species at Logan, such as Enterographa crassa, Ramalina canariensis and Schismatomma cretaceum, on which evidence a lichenologist might judge Logan to be a sunnier and warmer locality (thus, species distribution maps can be applied by lichenologists to choose suitable holiday destinations!). The span of gardens within the PlantNetwork membership provides a broad sampling of contrasting climates across the British mainland, and monitoring lichen communities at these sites may provide a targeted way of measuring climate change impacts.

However, these climatic effects are for many regions confounded by the effects of historic and present-day pollutants. Lichens were devastated across much of Britain by impacts associated with acid rain. Following efforts to clean up our industrial activities, lichens are now beginning to recolonize many of our urban areas. The most celebrated lichen in RBGE is Ramalina fraxinea, which is extremely sensitive to pollution, and was last seen in the Edinburgh area in the late 18th century. It is common in clean-air regions 
A.

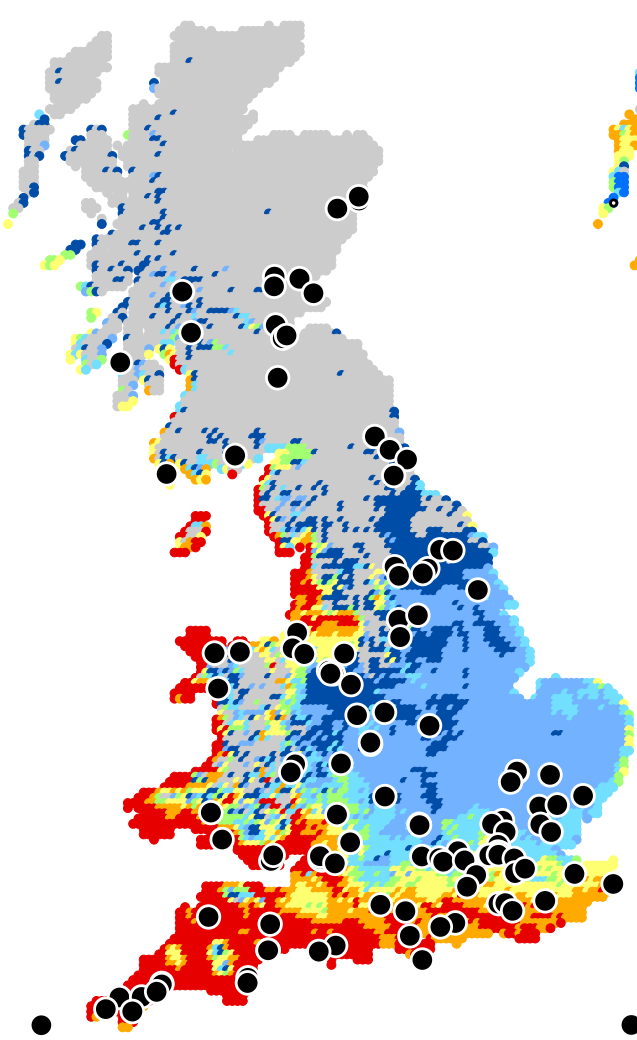

B.

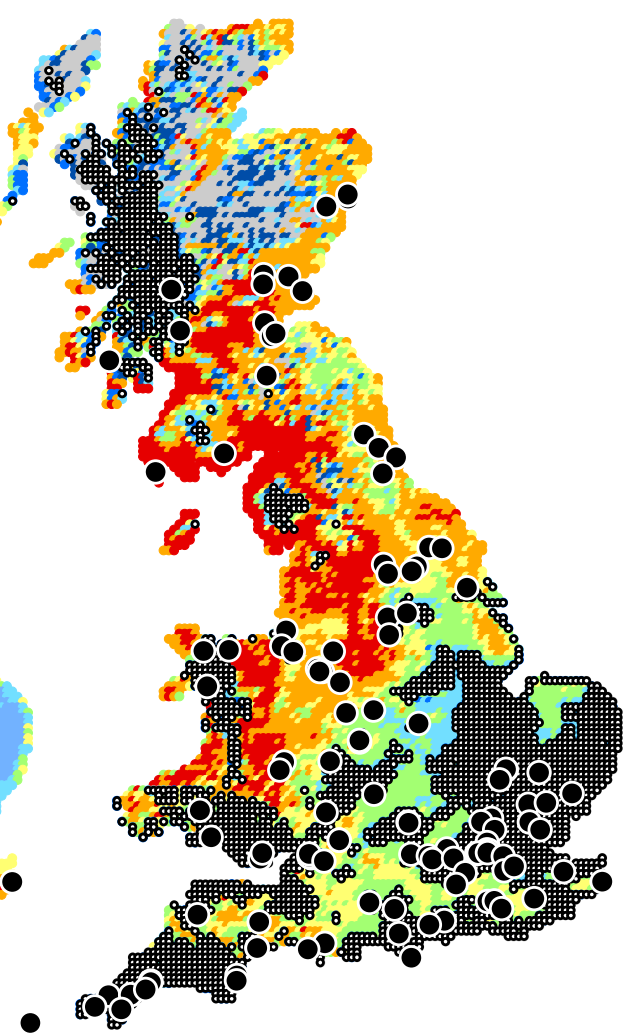

Fig. 4 Map A shows the modelled distribution for a suite of 'southern' lichen species, based on presentday climate (red $=$ areas of greatest suitability, through blue to grey $=$ absent). Map B shows the projected distribution for the same species during the 2050s based on an IPCC high greenhouse-gas emissions scenario. Stippling shows areas of key uncertainty for these species (for example non-analogue climates). Black dots show PlantNetwork sites (where information was available). Lichen species are expected to shift northwards; however, monitoring in botanic gardens could be used to confirm this trend, and to better understand impacts in areas of uncertainty.

of north-east Scotland, and its reappearance is an encouraging though tentative early sign of biodiversity returning to our cities (Fig. 3). More recently, lichens have been impacted by the effects of over-enrichment, and they are proving extremely sensitive to the excessive loading of nitrogen and phosphorus into the environment. This amalgam of effects leaves biodiversity scientists with a series of conundrums. For example, recent climate impact models suggest lichen species which today occur mostly in southern England are expected to shift northwards. However, (i) these species are currently absent from polluted regions of south-east England and (ii) the climate of south-east England in the future (for example the 2050s) is likely to be drier and warmer than settings experienced by these same species in Britain today. As the climate continues to change and as we simultaneously drive down pollution levels, which lichens will recolonize areas in 
south-east England, species from our existing flora, or species from southern Europe? In habitat management terms, should we prepare the ground to protect our native species, or to welcome colonists from the south? Only systematic monitoring schemes hold definitive answers to these and many similar questions, and the network of botanic gardens is well positioned to tease apart the complex interacting effects of pollution and climate impacts (Fig. 4).

\section{EDUCATION}

As we drive down pollution loads, the reappearance of lichens in our cities has thrown up an interesting case in public perception. Many generations of city dwellers and urbanites have learned from their immediate surroundings that tree-trunks are cylinders, perhaps with some fissures and wrinkles, but basically naked. People are used to seeing tree bark. Country folk know that trees in their 'natural' state are clothed in a rich cloak of epiphytes. As these epiphytes reappear in our cleaned-up cities, alarmed letters are sent to botanic gardens from the general public about the harmful new growths appearing on the shrubbery. Unfortunately, the reappearance of epiphytes is perhaps encouraged during the natural senescence of a shrub, as it collapses outwards, and its canopy thins, allowing more light to reach into the shrub's branches. There may be a correlation between lichen biomass and shrub decay, but there is no evidence for widespread damage to healthy trees by lichen epiphytes.

The reappearance of lichens, which should be celebrated as evidence of our triumph over harmful pollution, instead holds a major challenge. Lovers of nature should hope that more and more lichens colonize into our gardens. There is a demonstrable link between the diversity of lichen epiphytes, the diversity of invertebrates, and the health of bird populations. Lichens are part of the web of life. In contrast, many people express alarm at these new and unfamiliar growths. It is interesting that at one level epiphyterich trees are a source of wonderment (think of the 'Ents' in The Lord of the Rings, or the fascination of 'elfin' forests), while in actuality many people seem wary of the re-encroachment of this unfamiliar aspect of nature into our familiar urban landscape. People are naturally wary of the things they don't understand. There is therefore a role here for education by botanic gardens, to explain what these lichens mean, and how they can be interpreted as a positive sign. After all, the British Isles should be strongly celebrated for their diversity of lichens. There are c. 1,800 lichen species in Britain, ranging from arctic-alpine rarities in our mountains, to temperate rainforest along the west coast, dripping with epiphytes and equal in status to those in New Zealand, or along the Pacific Northwest coast. It is a cause for celebration that sensitive yet tenacious lichens are now returning to our botanic gardens. 


\section{ACKNOWLEDGEMENTS}

The vision of PlantNetwork in organizing a conference on Mosses, Ferns and Lichens in Gardens, and an invitation to speak at the conference, are gratefully acknowledged. I thank Brian Coppins for his advice on regional variation in the lichen flora of botanic gardens, and Rebecca Yahr for comments on this manuscript. 